\title{
Botulinum Toxin A Injection into the Subscapularis Muscle to Treat Intractable Hemiplegic Shoulder Pain
}

\author{
Jeong-Gue Choi, MD, Joon-Ho Shin, MD, MS, Bo-Ra Kim, MD
}

Department of Rehabilitation Medicine, National Rehabilitation Center, Seoul, Korea

\begin{abstract}
Objective To evaluate the beneficial effect of botulinum toxin A (Botox) injection into the subscapularis muscle on intractable hemiplegic shoulder pain.

Methods Six stroke patients with intractable hemiplegic shoulder pain were included. Botulinum toxin A was injected into the subscapularis muscle. Intractable hemiplegic shoulder pain was evaluated using an 11-point numerical rating scale. Pain-free range of motion was assessed for shoulder abduction and external rotation. The spasticity of the shoulder internal rotator was measured using the modified Ashworth scale. Assessments were carried out at baseline and at 1, 2, 4, and, if possible, 8 weeks.

Results Intractable hemiplegic shoulder pain was improved $(\mathrm{p}=0.004)$ after botulinum toxin injection into the subscapularis muscle. Restricted shoulder abduction $(\mathrm{p}=0.003)$, external rotation $(\mathrm{p}=0.005)$, and spasticity of the shoulder internal rotator $(\mathrm{p}=0.005)$ were also improved. Improved hemiplegic shoulder pain was correlated with improved shoulder abduction $(\mathrm{r}=-1.0, \mathrm{p}<0.001)$, external rotation $(\mathrm{r}=-1.0, \mathrm{p}<0.001)$, and spasticity of the internal rotator $(\mathrm{r}=1.0, \mathrm{p}<0.001)$.

Conclusion Botulinum toxin A injection into the subscapularis muscle appears to be valuable in the management of intractable hemiplegic shoulder pain.
\end{abstract}

Keywords Hemiplegia, Shoulder pain, Intractable pain, Type A botulinum toxins, Intramuscular injections

\section{INTRODUCTION}

Hemiplegic shoulder pain (HSP) is a common complication after stroke with a reported prevalence of $29 \%-65 \%$ $[1,2]$. HSP inhibits recovery and rehabilitation and im- pairs the quality of life of stroke survivors. Although the etiology of HSP is not well known, it has been suggested that multiple factors contribute to HSP, such as adhesive capsulitis, rotator cuff disorder, myofascial pain, complex regional pain syndrome, and shoulder hand syndrome

Received October 7, 2015; Accepted October 21, 2015

Corresponding author: Bo-Ra Kim

Department of Rehabilitation Medicine, National Rehabilitation Center \& Hospital, 58 Samgaksan-ro, Gangbuk-gu, Seoul 01022, Korea. Tel: +82-2-9011634, Fax: +82-2-901-1899, E-mail: bbora1114@naver.com

ORCID: Jeong-Gue Choi (http://orcid.org/0000-0002-4147-2050); Joon-Ho Shin (http://orcid.org/0000-0001-6447-8829); Bo-Ra Kim (http://orcid. org/0000-0003-1068-9246).

(c) This is an open-access article distributed under the terms of the Creative Commons Attribution Non-Commercial License (http://creativecommons.org/ licenses/by-nc/4.0) which permits unrestricted noncommercial use, distribution, and reproduction in any medium, provided the original work is properly cited. Copyright (c) 2016 by Korean Academy of Rehabilitation Medicine 
[3-5].

Physiatrists have applied use a wide variety of approaches against HSP, including correct positioning, physical therapy, neuromuscular electrical stimulation, modalities (hot pack, infrared, and interferential current therapy), oral medication, and local injection $[5,6]$. HSP in the first 6 months after stroke has a favorable outcome in $80 \%$ of patients [7]. However, a large number of patients suffer from intractable hemiplegic shoulder pain (iHSP), which is defined as non-remitting post-stroke shoulder pain $\geq 3$ months refractory to conventional therapies $[8,9]$. In addition, individuals with iHSP have limited treatment options.

Botulinum toxin type A (BTX) has been widely used to treat many conditions including spasticity, dystonia, myoclonus, muscle spasm, myofascial pain syndrome, paroxysmal autonomic instability with dystonia, and autonomic overactivity syndromes $[10,11]$. BTX was recently introduced as a novel treatment option for a variety of pain syndromes including shoulder pain [12-14]. A recent systematic review concluded that BTX injections had a better effect on shoulder pain than conventional therapies (steroid or placebo injection) [15]. Most studies applied BTX injections at the glenohumeral joint, subacromial bursa, pectoralis major, subscapularis, and other muscles. Interestingly, BTX injections into the subscapularis have shown therapeutic effects in the case of HSP $[12,16,17]$. Yelnik et al. [12] reported that BTX injections into the subscapularis muscle for spastic HSP result in better improvements in shoulder pain, range of motion (ROM) and spasticity compared to the placebo group.

Nevertheless, studies on the therapeutic effect of BTX injection into the subscapularis muscle for iHSP are lacking. Therefore, the aim of this study was to determine the efficacy of BTX injections into the subscapularis muscle in the patients with iHSP.

\section{MATERIALS AND METHODS}

\section{Subjects and methods}

For the purpose of this study, we defined iHSP by refining Singh et al. [8]'s criteria for refractory shoulder pain and Roosink et al. [9]'s criteria for persistent post-stroke shoulder pain. Eligible patients met all of the following inclusion criteria: (1) hemiplegic shoulder pain was de- fined as shoulder pain confined to the shoulder and/or C5 dermatome of the affected side during rest and/or active and/or passive motion after stroke onset; (2) non-remitting shoulder pain $\geq 3$ months; (3) pain score $\geq 4.5$ on a 0-10 numerical rating scale; and (4) inadequate or no response to conventional treatment including intra-articular corticosteroid injection ( $\geq 3$ injections). Exclusion criteria were (1) previous history of BTX injection into the subscapularis muscle; (2) clinical examination finding indicating that acromioclavicular disease or rotator cuff disease was the primary source of the shoulder pain; (3) complex regional pain syndrome diagnosed according to clinical diagnostic criteria proposed by Harden et al. [18]; (4) central post-stroke pain diagnosed according to the grading system proposed by Klit et al. [19]; (5) shoulder joint malignancy, prosthetic shoulder joint, or planned shoulder joint surgery in the next 6 months; (6) known allergy to BTX; and (7) unstable and serious medical condition or psychiatric disorder. Demographic and clinical data including age, sex, interval between stroke and injection, cause of stroke, and Brunnstrom stage of the affected upper arm were recorded. Conventional therapy factors that might affect the iHSP, such as modality, medication, and physical therapy, were recorded. This study was conducted in accordance with the Declaration of Helsinki and approved by National Rehabilitation Center Institutional Review Board.

\section{Study protocol}

A retrospective chart review was performed of 6 patients with iHSP treated in a rehabilitation hospital in Korea between September 2013 and August 2015.

\section{Intervention}

BTX (Botox; Allergan Inc., Irvine, KY, USA) injection into the subscapularis muscle was performed as previously described. An ultrasonography-guided lateral approach or conventional medial approach was made according to the patients' anatomical differences [20,21]. The needle was used as a stimulation electrode to detect the motor point at which minimal stimulation induces maximal internal rotation. BTX dosage was selected by various patient characteristics such as body weight and spasticity severity. Thus, $60-80$ units of BTX were administered in each injection. Physical therapy (capsular stretching, distraction, passive range of motion [PROM] 
exercise), modality (hot pack, infrared, interferential current therapy), and neuromuscular electrical stimulation of the shoulder muscles, such as the posterior fibers of the deltoid and supraspinatus muscles, were administered to all participants as before the injection.

\section{Outcome measures}

Pain severity was measured on an 11-point pain intensity numeric rating scale (PI-NRS), where 0 is no pain and 10 is the worst possible pain. Pain-free PROM of abduction and external rotation were assessed. Spasticity of shoulder internal rotator was measured using the modified Ashworth scale (MAS) rated on a scale of 0 (normal) to 4 (extreme). These measurements were carried out at baseline and at 1, 2, 4, and, if possible, 8 weeks after the intervention.

\section{Statistical analysis}

Statistical analyses were performed using SPSS software ver. 17.0 (SPSS Inc., Chicago, IL, USA). A non-parametric statistical test was used because of the small sample size in the study group. Freidman tests were used to compare measurements at baseline and follow-up after treatment. Correlations between PI-NRS and pain-free PROM or MAS of the affected shoulder were investigated using the Spearman test. The level of statistical significance was set at $\mathrm{p}<0.05$.

\section{RESULTS}

Patients with iHSP included 5 men and 1 woman with a mean age of $55.6 \pm 11.1$ years (Table 1). The Brunnstrom stage of the affected proximal upper limb was 3 in all subjects. The median PI-NRS was 8.0 (interquartile range, 6.0-9.3) in patients before the BTX injection. BTX injections were done at 8.0 (interquartile range, 6.8-11.3) months after stroke onset.

All patients were assessed at baseline and followed up at weeks 1, 2, and 4 after the BTX injection. Two of these patients were also followed up at week 8 . The detailed

Table 1. Characteristics of patients suffering from intractable hemiplegic shoulder pain

\begin{tabular}{|c|c|c|c|c|c|c|c|}
\hline $\begin{array}{l}\text { Patient } \\
\text { no. }\end{array}$ & $\begin{array}{l}\text { Sex/ } \\
\text { age } \\
(\mathbf{y r})\end{array}$ & $\begin{array}{l}\text { Stroke } \\
\text { cause }\end{array}$ & $\begin{array}{c}\text { Brunnstrom } \\
\text { stage of } \\
\text { upper } \\
\text { extremity }\end{array}$ & $\begin{array}{c}\text { Time } \\
\text { between } \\
\text { stroke and } \\
\text { BTX } \\
\text { injection } \\
\text { (mo) }\end{array}$ & $\begin{array}{c}\text { NRS for } \\
\text { shoulder } \\
\text { pain before } \\
\text { BTX } \\
\text { injection }\end{array}$ & $\begin{array}{l}\text { Spasticity of the } \\
\text { internal rotator } \\
\text { of the affected } \\
\text { shoulder before } \\
\text { BTX injection } \\
\text { (MAS grade) }\end{array}$ & $\begin{array}{l}\text { Therapy for } \\
\text { hemiplegic } \\
\text { shoulder } \\
\text { pain before } \\
\text { BTX injection }\end{array}$ \\
\hline 1 & $\mathrm{M} / 57$ & $\begin{array}{l}\text { Rt. MCA } \\
\text { infarction }\end{array}$ & 3 & 7 & 8 & 3 & $\begin{array}{l}\text { IR/ICT, NMES on } \\
\text { supraspinatus, deltoid, } \\
\text { physical therapy }\end{array}$ \\
\hline 2 & $F / 39$ & $\begin{array}{l}\text { Rt. MCA } \\
\text { infarction }\end{array}$ & 3 & 18 & 6 & 3 & $\begin{array}{l}\text { IR/ICT, NMES on } \\
\text { supraspinatus, deltoid, } \\
\text { physical therapy }\end{array}$ \\
\hline 3 & $\mathrm{M} / 64$ & Rt. BG ICH & 3 & 6 & 8 & 3 & $\begin{array}{l}\text { IR/ICT, NMES on deltoid, } \\
\text { physical therapy }\end{array}$ \\
\hline 4 & $\mathrm{M} / 71$ & $\begin{array}{l}\text { Rt. MCA } \\
\text { infarction }\end{array}$ & 3 & 8 & 10 & 3 & $\begin{array}{l}\text { IR/ICT, NMES on } \\
\text { supraspinatus, deltoid, } \\
\text { physical therapy }\end{array}$ \\
\hline 5 & $\mathrm{M} / 51$ & $\begin{array}{l}\text { Lt. MCA } \\
\text { infarction }\end{array}$ & 3 & 9 & 6 & 2 & $\begin{array}{l}\text { IR/ICT, NMES on } \\
\text { supraspinatus, deltoid, } \\
\text { physical therapy }\end{array}$ \\
\hline 6 & $\mathrm{M} / 53$ & $\begin{array}{l}\text { Rt. MCA } \\
\text { and ACA } \\
\text { infarction }\end{array}$ & 3 & 8 & 9 & 3 & $\begin{array}{l}\text { IR/ICT, NMES on } \\
\text { supraspinatus, deltoid, } \\
\text { physical therapy }\end{array}$ \\
\hline
\end{tabular}

M, male; F, female; BTX, botulinum toxin type A; NRS, numeric rating scale; MAS, modified Ashworth scale; ACA, anterior cerebral artery; MCA, middle cerebral artery; BG, basal ganglia; ICH, intracerebral hemorrhage; IR/ICT, infrared/interferential current therapy; NMES, neuromuscular electrical stimulation. 
clinical courses of the PI-NRS, pain-free PROM of the shoulder, and MAS for the shoulder internal rotator were shown in Figs. 1, 2, and 3, respectively.

As shown in Figs. 1-3, PI-NRS and MAS for the shoulder internal rotator were decreased and pain-free PROM for the shoulder were increased after BTX injection into the subscapularis muscle. Statistically significant differences were found between baseline and follow-up measurements after 1, 2, and 4 weeks in PI-NRS ( $\mathrm{p}=0.004)$, painfree PROM of shoulder abduction ( $\mathrm{p}=0.003)$, external rotation ( $p=0.005)$, and MAS for the shoulder internal rotator $(\mathrm{p}=0.005)$ using the Freidman test. Post-hoc testing showed no statistically significant differences in measurements.

There were significant correlations between PI-NRS for iHSP and pain-free PROM for shoulder abduction ( $\mathrm{r}=-1.0$, $\mathrm{p}<0.001$ ), external rotation ( $\mathrm{r}=-1.0, \mathrm{p}<0.001)$, and MAS for the shoulder internal rotator $(\mathrm{r}=1.0, \mathrm{p}<0.001)$ using the Spearman test.

Pain medications (nonsteroidal anti-inflammatory drugs, oral opioids, acetaminophen, anticonvulsant, tricyclic anti-depressants) were taken by patients prior to the BTX injection. Two of 6 patients (33.3\%) reduced their medication doses and 4 of 6 patients $(66.7 \%)$ continued taking the same dose after the BTX injection. Furthermore, some of the subjects reported improvements in sleep, mood, and participation in a rehabilitation program. There were no significant adverse effects, particularly significant motor weaknesses, preventing participation in a rehabilitation program or basic activities of daily living.

\section{DISCUSSION}

The main finding of this study was that BTX injection into the subscapularis muscle improved shoulder pain, ROM, and spasticity in patients with iHSP. The improved shoulder pain was correlated with improved pain-free PROM of the shoulder and spasticity of the shoulder internal rotator.

The subscapularis muscle is one of the primary internal rotators of the shoulder and plays a key role in synergic patterns [22]. Interestingly, restricted shoulder ROM is reportedly an important element in a vicious cycle leading to persistent HSP ( $>6$ months) [9]. In this study, all of the subjects with iHSP were in Brunnstrom stage 3 and exhibited typical synergic movements, postures, restricted shoulder ROM, and spasticity. Therefore, we suspected that the main source of iHSP was spasticity of the shoulder internal rotator. Together, BTX injection into the subscapularis might decrease the spasticity of the strong shoulder internal rotator, leading to restoration of restricted ROM for shoulder external rotation and finally alleviating iHSP by breaking its vicious cycle. This was supported by the high correlation between ROM or spasticity and pain in our results.

Until now, subscapularis nerve block, transection of the subscapularis tendon, and BTX injection into the subscapularis muscle have been attempted to treat spasticity of the subscapularis and its sequelae $[12,16,23,24]$.

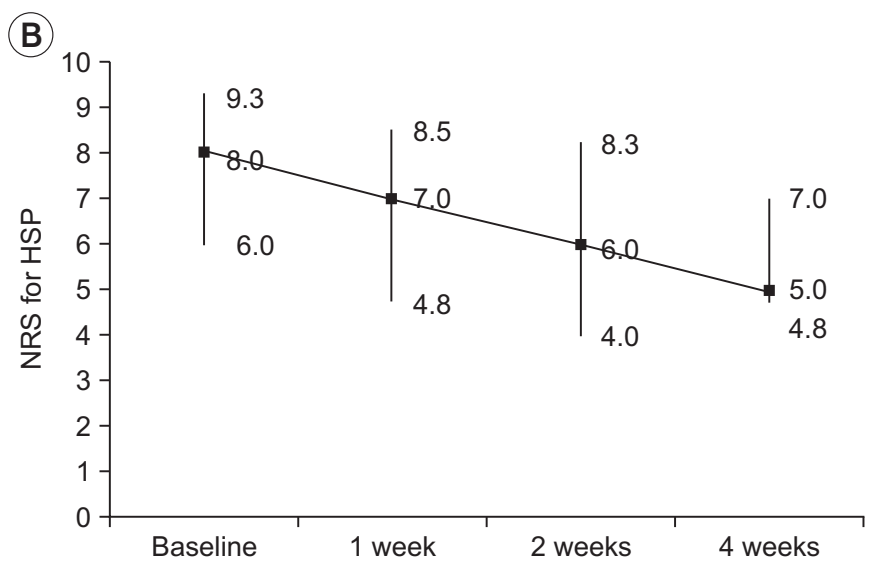

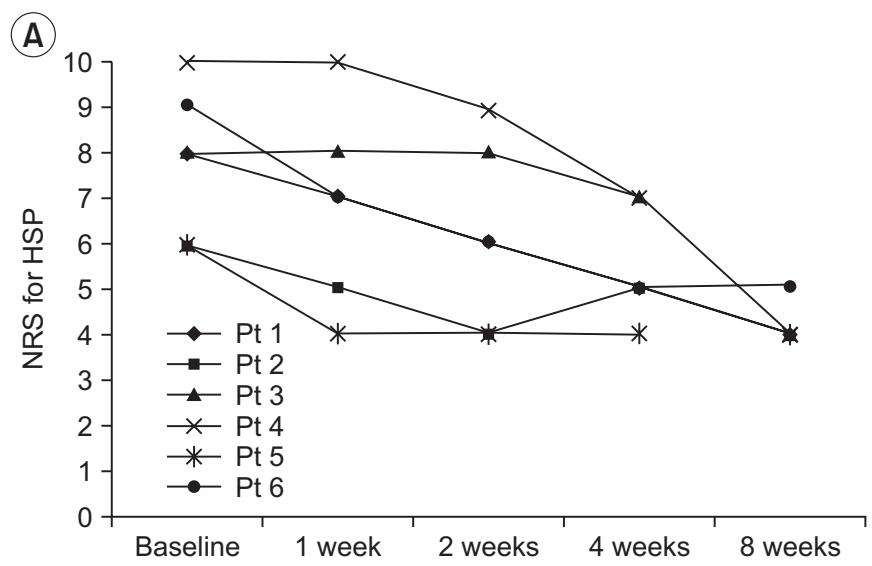

Fig. 1. Progression of the PI-NRS for iHSP during follow-up measurements (A) and improvement of median (interquartile range) in PI-NRS during the study (B). The Friedman test revealed a statistically significant effect of time $(\mathrm{p}=0.004)$. Post-hoc testing showed no statistically significant differences over time. PI-NRS, pain intensity numeric rating scale; iHSP, intractable hemiplegic shoulder pain; HSP, hemiplegic shoulder pain; Pt, patient. 

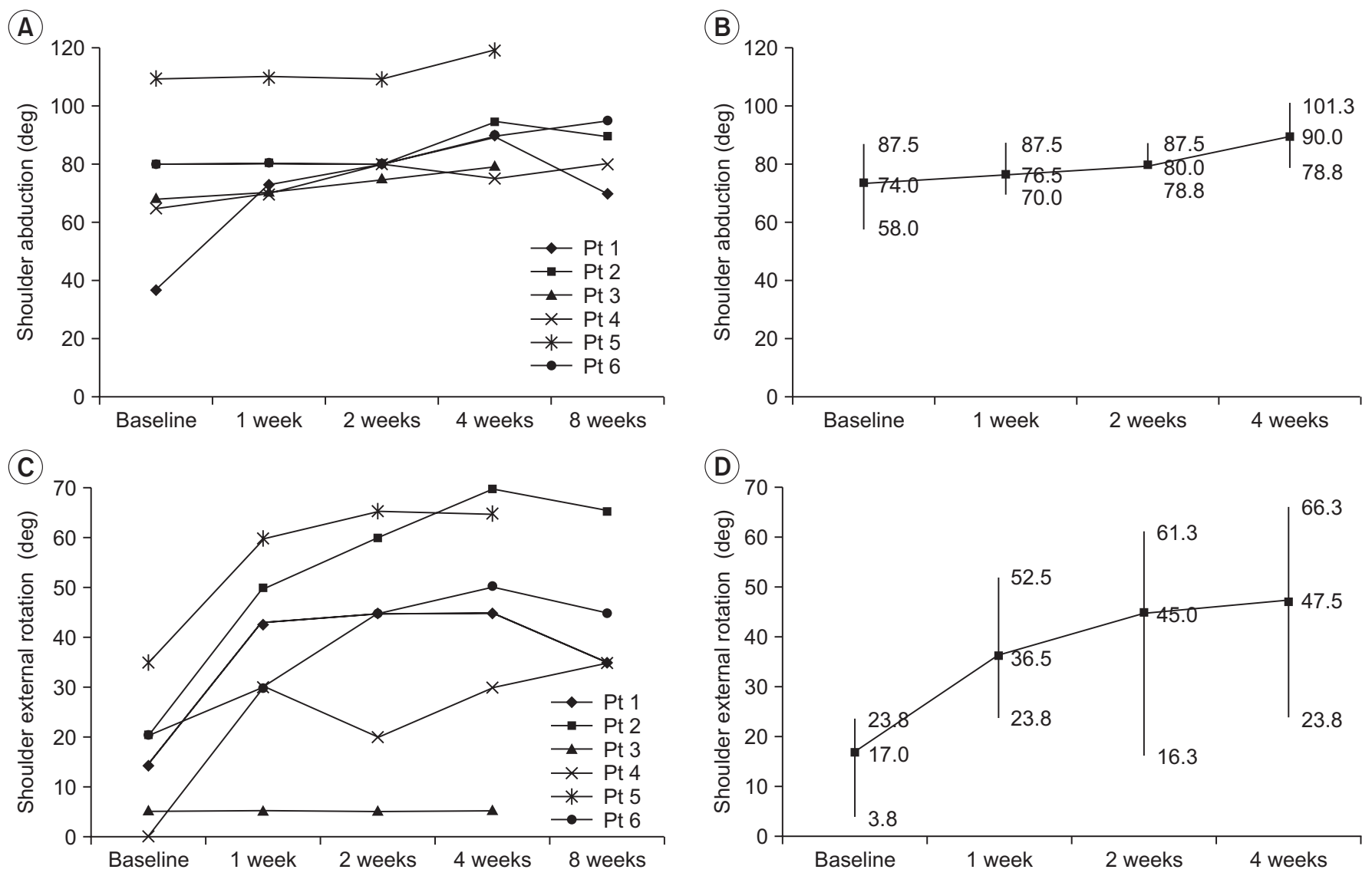

Fig. 2. Progression of pain-free PROM for shoulder abduction and external rotation during follow-up measurements (A, C) and improvement of median (interquartile range) in pain-free PROM for shoulder abduction and external rotation during the study (B, D). The Friedman test revealed a statistically significant effect of time on shoulder abduction $(p=0.003)$ and external rotation $(p=0.005)$. Post-hoc testing showed no statistically significant differences over time. PROM, passive range of motion; Pt, patient.
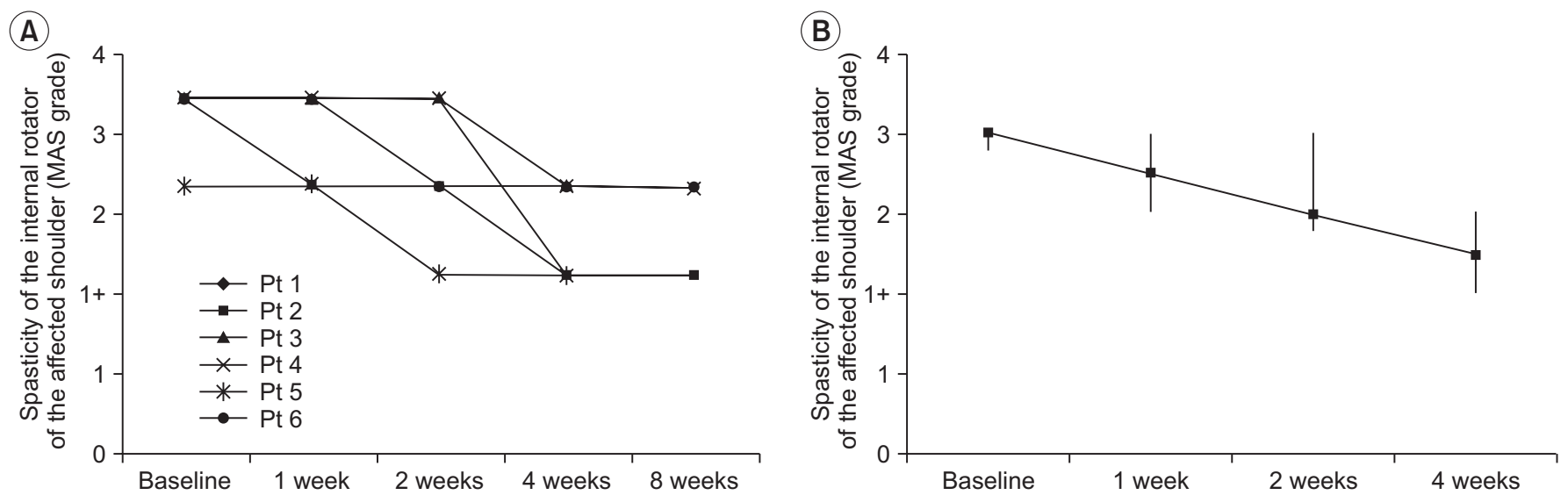

Fig. 3. Progression of the spasticity of the internal rotator of the affected shoulder (MAS grade) during follow-up measurements (A) and improvement of median (interquartile range) MAS grade of the internal rotator of the affected shoulder during this study (B). The Friedman test revealed a statistically significant effect of time on the spasticity of shoulder internal rotator $(\mathrm{p}=0.005)$. Post-hoc testing showed no statistically significant differences over time. MAS, modified Ashworth scale; Pt, patient. 
These interventions showed significant improvement in shoulder PROM of abduction/external rotation and pain, except in one study by de Boer et al. [16]. They reported that BTX injection into the subscapularis muscle had no effects on shoulder PROM and pain. This difference from our result might be due to the participants' characteristics. The current participants suffered from more severe pain and spasticity (mean PI-NRS, 8.0; mean MAS, 3.0; and Brunnstrom stage 3) than previous study's participants (mean PI-NRS, 4.6; mean MAS, 2.0; and Brunnstrom stage 2). Therefore, the BTX injection might have failed to show efficacy due to less severe pain and spasticity.

Another postulated mechanism of our result was the anti-nociceptive effect of BTX. BTX has a direct analgesic effect by inhibiting neuropeptide release at nociceptive nerve endings, although the pathogenic mechanism of spasticity-associated pain and its alleviating effect have not yet been fully established [25]. As seen in patient \#3, who showed improved iHSP without any PROM change, effects other than PROM improvement might play a role in pain improvement. This analgesic effect was also reported in spasticity-associated pain $[14,26]$. Therefore, the anti-nociceptive effects of BTX not obtainable by other interventions help improve iHSP.

It should be noted that our study's results could not be explained by the consequence of BTX injection alone. According to a previous study, the anti-spastic effect after BTX injection occurs within 3 days, peaks at 2 weeks, and is reversed after 2 weeks [27-29]. However, in this study, improvements in shoulder pain and shoulder mobility persisted beyond 2 weeks. Thus, not only the BTX injection, but also the continuously applied physical therapy consisting of correct positioning to improving shoulder mobility, played a crucial role. Therefore, intervention should be continuous and multidimensional to focus on maintaining and restoring pain free PROM for shoulder motion to alleviate iHSP.

The main limitations of the present study were its small sample size, lack of a control group, and retrospective nature of the data analysis. Therefore, its statistical power is too low to allow us to reach evident conclusions. Moreover, the follow-up durations were relatively short to identify the long-term effect of BTX injection into subscapularis muscles. BTX injection acts by diffusion from the injection site to the adjacent areas, and the estimated diffusion area is $4.5 \mathrm{~cm}^{2}$ [30]. For this reason, not only the subscapularis muscle but also the adjacent soft tissue influenced by the BTX injection might have contributed to the results of this study. Therefore, injections into other soft tissues could be considered in future studies.

In this study, after BTX injection into the subscapularis muscle, there were significant decreases in shoulder pain and spasticity. PROM limitations of the shoulder were also improved in patients with iHSP. Therefore, this result could suggest that BTX injection into the subscapularis muscle could be used as a novel additional treatment option for iHSP. Furthermore, future large randomized, controlled, and prospective studies are needed to confirm the beneficial effects of BTX injection in patients with iHSP.

\section{CONFLICT OF INTEREST}

No potential conflict of interest relevant to this article was reported.

\section{ACKNOWLEDGMENTS}

This study was supported by a grant (No. NRCTR-IN 14002) of the Translational Research Center for Rehabilitation Robots, National Rehabilitation Center, Ministry of Health \& Welfare, Korea.

\section{REFERENCES}

1. Adey-Wakeling Z, Arima H, Crotty M, Leyden J, Kleinig T, Anderson CS, et al. Incidence and associations of hemiplegic shoulder pain poststroke: prospective population-based study. Arch Phys Med Rehabil 2015;96:241-7.e1.

2. Aras MD, Gokkaya NK, Comert D, Kaya A, Cakci A. Shoulder pain in hemiplegia: results from a national rehabilitation hospital in Turkey. Am J Phys Med Rehabil 2004;83:713-9.

3. Lo SF, Chen SY, Lin HC, Jim YF, Meng NH, Kao MJ. Arthrographic and clinical findings in patients with hemiplegic shoulder pain. Arch Phys Med Rehabil 2003;84:1786-91.

4. Tavora DG, Gama RL, Bomfim RC, Nakayama M, Silva CE. MRI findings in the painful hemiplegic shoulder. Clin Radiol 2010;65:789-94. 
5. Murie-Fernandez M, Carmona Iragui M, Gnanakumar V, Meyer M, Foley N, Teasell R. Painful hemiplegic shoulder in stroke patients: causes and management. Neurologia 2012;27:234-44.

6. Snels IA, Beckerman H, Lankhorst GJ, Bouter LM. Treatment of hemiplegic shoulder pain in the Netherlands: results of a national survey. Clin Rehabil 2000;14:20-7.

7. Gamble GE, Barberan E, Laasch HU, Bowsher D, Tyrrell PJ, Jones AK. Poststroke shoulder pain: a prospective study of the association and risk factors in 152 patients from a consecutive cohort of 205 patients presenting with stroke. Eur J Pain 2002;6:467-74.

8. Singh JA, Mahowald ML, Noorbaloochi S. Intra-articular botulinum toxin A for refractory shoulder pain: a randomized, double-blinded, placebo-controlled trial. Transl Res 2009;153:205-16.

9. Roosink M, Renzenbrink GJ, Buitenweg JR, Van Dongen RT, Geurts AC, IJzerman MJ. Persistent shoulder pain in the first 6 months after stroke: results of a prospective cohort study. Arch Phys Med Rehabil 2011;92:1139-45.

10. Jankovic J. Botulinum toxin in clinical practice. J Neurol Neurosurg Psychiatry 2004;75:951-7.

11. Lee HS, Oh HS, Shin JH. Paroxysmal autonomic instability with dystonia managed using chemodenervation including alcohol neurolysis and botulinum toxin type a injection: a case report. Ann Rehabil Med 2015;39:308-12.

12. Yelnik AP, Colle FM, Bonan IV, Vicaut E. Treatment of shoulder pain in spastic hemiplegia by reducing spasticity of the subscapular muscle: a randomised, double blind, placebo controlled study of botulinum toxin A. J Neurol Neurosurg Psychiatry 2007;78:845-8.

13. Jabbari B. Botulinum neurotoxins in the treatment of refractory pain. Nat Clin Pract Neurol 2008;4:676-85.

14. Wissel J, Muller J, Dressnandt J, Heinen F, Naumann M, Topka H, et al. Management of spasticity associated pain with botulinum toxin A. J Pain Symptom Manag 2000;20:44-9.

15. Wu T, Fu Y, Song HX, Ye Y, Dong Y, Li JH. Effectiveness of botulinum toxin for shoulder pain treatment: a systematic review and meta-analysis. Arch Phys Med Rehabil 2015;96:2214-20.

16. de Boer KS, Arwert HJ, de Groot JH, Meskers CG, Mishre AD, Arendzen JH. Shoulder pain and exter- nal rotation in spastic hemiplegia do not improve by injection of botulinum toxin A into the subscapular muscle. J Neurol Neurosurg Psychiatry 2008;79:581-3.

17. Lim JY, Koh JH, Paik NJ. Intramuscular botulinum toxin-A reduces hemiplegic shoulder pain: a randomized, double-blind, comparative study versus intraarticular triamcinolone acetonide. Stroke 2008;39:12631.

18. Harden RN, Bruehl S, Stanton-Hicks M, Wilson PR. Proposed new diagnostic criteria for complex regional pain syndrome. Pain Med 2007;8:326-31.

19. Klit H, Finnerup NB, Jensen TS. Central post-stroke pain: clinical characteristics, pathophysiology, and management. Lancet Neurol 2009;8:857-68.

20. Yelnik AP, Colle FM, Bonan IV. Treatment of pain and limited movement of the shoulder in hemiplegic patients with botulinum toxin A in the subscapular muscle. Eur Neurol 2003;50:91-3.

21. Rha DW, Han SH, Kim HJ, Won SY, Lee SC. Ultrasound-guided lateral approach for needle insertion into the subscapularis for treatment of spasticity. Arch Phys Med Rehabil 2012;93:1147-52.

22. Chang YW, Hughes RE, Su FC, Itoi E, An KN. Prediction of muscle force involved in shoulder internal rotation. J Shoulder Elbow Surg 2000;9:188-95.

23. Hecht JS. Subscapular nerve block in the painful hemiplegic shoulder. Arch Phys Med Rehabil 1992;73:1036-9.

24. Braun RM, West F, Mooney V, Nickel VL, Roper B, Caldwell C. Surgical treatment of the painful shoulder contracture in the stroke patient. J Bone Joint Surg Am 1971;53:1307-12.

25. Mense S. Neurobiological basis for the use of botulinum toxin in pain therapy. J Neurol 2004;251 Suppl 1:I1-7.

26. Jabbari B, Machado D. Treatment of refractory pain with botulinum toxins: an evidence-based review. Pain Med 2011;12:1594-606.

27. Cosgrove AP, Corry IS, Graham HK. Botulinum toxin in the management of the lower limb in cerebral palsy. Dev Med Child Neurol 1994;36:386-96.

28. Childers MK, Brashear A, Jozefczyk P, Reding M, Alexander D, Good D, et al. Dose-dependent response to intramuscular botulinum toxin type A for upper-limb spasticity in patients after a stroke. Arch Phys Med Rehabil 2004;85:1063-9. 
29. Angaut-Petit D, Molgo J, Comella JX, Faille L, Tabti N. Terminal sprouting in mouse neuromuscular junctions poisoned with botulinum type A toxin: morphological and electrophysiological features. Neuroscience 1990;37:799-808.
30. Marco E, Duarte E, Vila J, Tejero M, Guillen A, Boza R, et al. Is botulinum toxin type A effective in the treatment of spastic shoulder pain in patients after stroke? A double-blind randomized clinical trial. J Rehabil Med 2007;39:440-7. 